\title{
Correction to: Testing the construct validity of competing measurement approaches to probed mind-wandering reports
}

\author{
Michael J. Kane ${ }^{1} \cdot$ Bridget A. Smeekens ${ }^{1} \cdot$ Matt E. Meier ${ }^{2} \cdot$ Matthew S. Welhaf $^{1} \cdot$ Natalie E. Phillips ${ }^{1}$
}

Published online: 10 September 2021

(C) The Psychonomic Society, Inc. 2021

\section{Correction to: Behavior Research Methods} https://doi.org/10.3758/s13428-021-01557-x

In this article, the content of footnote 6 was omitted. The omitted footnote text read as follows:

"6. Cheyne et al. (2009) may provide a starting point for this measurement pursuit, as their model of attention lapses proposed different types of performance errors to result from different gradations (or severities) of attentional withdrawal from the SART."

Publisher's note Springer Nature remains neutral with regard to jurisdictional claims in published maps and institutional affiliations.

The online version of the original article can be found at https://doi.org/ 10.3758/s13428-021-01557-x

Michael J. Kane mjkane@uncg.edu

1 Department of Psychology, University of North Carolina at Greensboro, P.O. Box 26170, Greensboro, NC 27402-6170, USA

2 Western Carolina University, Cullowhee, NC 28723, USA 